\title{
Reverse Innovation: An Exploratory Study on Tata Nano Motors
}

\author{
Bridget Chipanje $^{1}$, Dong Ying ${ }^{2} \quad$ Lv Haiping ${ }^{3}$ \\ Department of International Business Management, \\ Zhejiang University of Science and Technology, Hangzhou, PR. CN.
}

\begin{abstract}
This article unpacks the concept of reverse innovation by studying the Nano version of the Tata engine, the cheapest car in the world to be unveiled in India. The document examines the concept process, product development and marketing strategy used by the company. Nano was made with the people of India in mind, so it was the first local production for local buyers before it exports to the developed world, the development of Nano products became known for its cost-saving features, which initially influenced the price of promotion, but later increased due to car innovations. The car is known for its cost-cutting features, such as three walnut camera wheels, access to the trunk from the inside and a windshield wiper. The price was marked at $\$ 2,000$, which was equivalent to a motorcycle. Some notable aspects that led to Tata Nano's success include the recruitment of competent and trained human resources, creating synergies with chain offerings for easy distribution. But the company faced challenges ranging from looming safety standards causing a car fire, a longer wait for the vehicle and ultimately a marketing strategy that was unsustainable and ultimately led to a drop in sales.
\end{abstract}

Key words: Reverse innovation, emerging economies, Tata Nano motor

DOI: $10.7176 / \mathrm{JESD} / 12-6-11$

Publication date:March $31^{\text {st }} 2021$

\section{Introduction}

Reverse innovation means that when innovation is first introduced in poor or emerging countries before it "flows" to rich countries (Govindarajan; 2011). Reverse innovation takes place in emerging economies, focusing on local customers or the production of goods from emerging economies that hover upwards and are destined for rich countries. Cases of reverse upgrades are on the rise in various areas such as General Electric, ultra-costly sound scanning, Grameen Bank (microfinance), Bharti Airtell's ultra-cheap wireless phone, BYD electric car and Tata Nano. Reverse innovation in emerging economies brings new products to the market to address pressing local challenges and ensure that the availability of cheap products on the market is also attractive to growing middlewage earners. The aim of the study is to show the thoughts, development and marketing process of Tata Nano. The sharp decrease in nanolea costs and prices has led to demand for the product, which has prompted a drastic reduction in the cost-saving functions of the product. These factors, together with optimised marketing strategies with recruitment experts, have ensured the success of reverse innovations. The study acknowledges that a combination of factors such as the creation of a viable and direct distribution team allowed the company to sell more at the beginning of the nanovehicle. In addition, supply chain synergies ensured that the vehicle was constantly available in sales halls and in several designated locations where people visited and collaborated with financial institutions that not only sold the vehicle but helped farmers by lending to buy the vehicle. However, the company faced some limitations, such as longer waiting times for the car, safety concerns, stigmatization of all these factors, which then led to lower sales, which ultimately affected the company, and this led to the cessation of production of the Nano model.

\section{Unpacking the Concept of Reverse Innovation}

Maximilian (2009) describes reverse innovation as the launch of new products that were first introduced to new markets and sold in emerging countries. Scientists like Govindarajan and Ramamurti (2011) correctly define reverse innovation as "innovation first adopted in a porous country before adoption in a richer country." Reverse innovation includes a scenario in which innovation is applied for the first time in porous or emerging countries before the "muzzly" in richer countries. Immelt et al (2009) shows that reverse innovation is the opposite of "division," a system in which many industrial products develop in developed countries and are sold in porous countries. Seely-Brown and Hagel gave a flexible definition by introducing the term "revenge for innovation," which refers to innovative solutions from emerging economies. Reverse innovations are visible in several areas, such as General Electric in healthcare, Huawei in the technology sisterhood and Tata Motors in the mobile automotive industry 


\subsection{The development of Tata Nano motors}
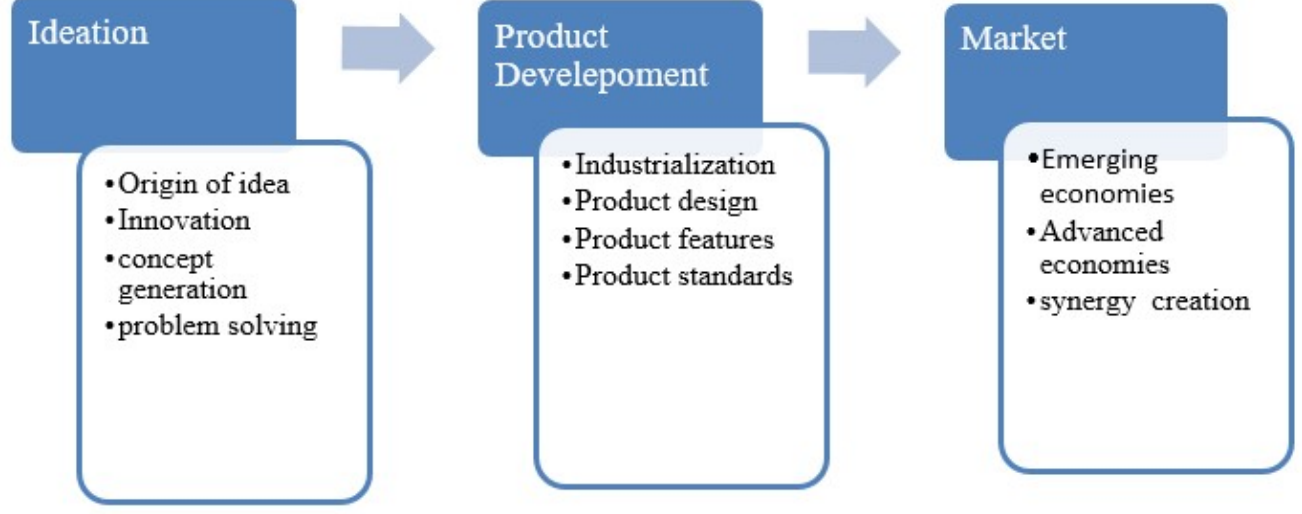

Source compiled by researcher 2020

Fig 1; Pictorial diagram depicting Tata Nano’s implementation of reverse innovation

2.2 Ideation and innovation; Mr Ratum Tata the chairman of Tata motors one of the biggest automobile conglomerate was motivated to come up with the idea of the Tata Nano vehicle model after he saw a family of four crammed on a two wheeler scooter, a traditional mode of transport used by the poor and middle income Indians (Aggrawal;2014) . After witnessing the ordeal of that family he described the mode of transport which was used by the family as unsafe considering that the roads were poorly maintained. As a result he was motivated to come up with an idea of solving the problem he had seen, the solution was to design and come up with a small, affordable vehicle and cheaply produced vehicle which would be afforded by the poor folks and middle income earners. The Tata Nano, 'worlds cheapest' car was pegged at \$2,200 a figure which could buy a motorcycle which was popular among the poor and middle income earners.

2.3 Concept generation; the concept was generated and executed by a team which had been handpicked by the chairman of the company to produce a small and cheap car. This idea resonate with the tenet of reverse innovation which indicate that to ensure complete success in reverse innovation, strong technical and managerial competencies have to be considered (Von Zedtwitz et al 2015).

2.4 Product development; the engineers speedily turned the idea into a practical reverse innovation product in the form of a Nano car. The concept of reverse innovation is premised on the idea that products must be cheaply produced, at the same time meeting the required safety and product standards (Govindarajan and Trimble; 2014). Seemingly so the Nano vehicle was cheaply produced and the engineers introduced some cost cutting features. Singh and Joshi (2015) cite that the Tata Nano model was uniquely produced and designed so that it could appeal to the motorcyclist and scooter riders and the middle income earners generally. The idea behind the creation of Tata Nano model was to innovate, a product which was attractive and also being an affordable and cost-effective means of transportation for the deprived while considering the customer's expectations and meeting the regulatory requirements (Corsi et al 2014). Tata motors embraced a new design of Nano to reduce the cost. In a bid to warrant spacious interior, lower weight and low costs, engine was strapped in the car's rear, with front wheel drive and the petrol tank to the front. This made the car more low-cost, efficient and compact. Material which included some fibre and plastics were opted for compared to steel to keep the weight of the car low. Singh and Joshi (2015) remind that the car did not have a radio, power windows, and air conditioning, anti-lock brakes, air bags, remote locks or power steering as a way of producing a low priced vehicle. 


\subsection{Product Features}

Table 1; indicate the cost cutting features of the Nano vehicle

Tata Nano's comparison with Maruti Alto 800, the closest competitor of the Nano

\begin{tabular}{|l|l|}
\hline Tata Nano & Maruti Alto 800 \\
\hline -One windscreen wiper instead of the usual two & -Two windscreen wipers \\
\hline -Three lug nuts per wheel & -Four lug nuts per wheel \\
\hline -No external fuel cap, fuel inlet accessed by opening the front hood & -External fuel cap \\
\hline $\begin{array}{l}\text {-Trunk was only accessible from inside the car, as the rear could not } \\
\text { open. Eventually upgraded in the year 2015 to a hatchback }\end{array}$ & $\begin{array}{l}\text {-One opening rear windscreen } \\
\text { but also got a full hatchback }\end{array}$ \\
\hline -No airbag on any model & -No airbag on any variant \\
\hline -Radio or CD player was optional & -Radio or CD player was optional \\
\hline
\end{tabular}

Source; Govindarajan and Trimble (2014)

\subsection{Marketing and Distribution strategies of the Nano model}

The Nano vehicle was created first for the emerging economy of India with the intention that later it would trickle down to developed markets, hence India. Govindarajan and Trimble (2014), cite that the targeted people were those who belonged to the bottom of the pyramid who owned two wheelers, but who sought to own a four wheeler which was beyond their pocket. The product was first of its kind to be innovated, designed specifically for middle income earners and the poor class consisting mostly of farmers and transporters. Unique and novel marketing strategies were adopted which had never been used for marketing purposes by any firm. Tata motors managed to keep their communication campaign innovative and cost-effective, Tata motor advertised their new brand through the use of print medium and radio. Other innovative strategies were adopted to complement the afore mentioned forms of marketing and these included the use of online Nano games, Nano chat rooms, social media platforms of Nano conversations on facebook, and blogs, Nano pop-ups on major websites launching Nano merchandise like baseball caps, key chains, and T-shirts etc. In addition, Westside, the Tata group-owned lifestyle retail chain, advertised Nano through text messages to customers (Richard, 2014). These forms of advertising ensured reaching a wider base of potential customers both in the city and periphery.

The distribution network of Tata Nano was unique as compared to other forms of distribution which have been used by other firms. The targeted clientele were poor and middle income earners, hence were frightened and hesitant to walk into large Tata Motors Ltd showrooms. To curb this and encourage people to buy the product a model was adopted of introducing some small retails and electronics megastore which did not frighten the customers (Westside and Chroma) outlets as well as auto dealerships (David; 2010) . The firm entered into agreements with some preferred banks / Non-Banking Financial institutions (NBFCs).Singh and Joshi (2015) indicate that new insurance schemes were co-designed with five partner insurance companies to enhance the sales and service network for better reach and service to the customers. The prospective customers had to book Nano with INR 3,500 with the banks. From the bookings a lottery system was adopted to select customers for delivery of cars. The method adopted by Tata motors was unique and it saved its purpose in ensuring that people got the vehicle through various platforms.

\section{Success type of the Tata Nano model}

Hiring appropriate human resource propelled to the success of the Tata motors, in successfully launching the Nano model. For reverse innovation to be successful knowledgeable and skilled personnel are needed hence such people were hired by the firm. The policy aspect was prioritised, educational policies were put in place and cascaded covering issues of safety and further indicating the significance of reverse innovation in emerging economies Furthermore another key success area of Tata motors was the creation of synergies in supply chain with other companies. Notable examples of such synergies which were created are that of Tata motors establishing an alliance with the German brand of Mercedes Benz, and later on purchasing Land Rover and Jaguar (Aschmonet and Janevska 2013). Shouldering with such brands has enabled market power and ensured successive reverse innovation (Govindarajan et.al 2012). Additionally the Nano model managed to penetrate new markets with the new product, although the product was received with mixed emotions but what but the product essentially appealed to the middle income earners and the afforded an opportunity for people to buy a brand new car. 


\section{Challenges to the Tata Nano}

Nano faced a number of challenges, including a mixed reception from Indian customers. This was because the car was still expensive compared to the motorcycle, forcing customers to keep buying the motorcycle. The manufacturer's continued improvement in cars led the price of the car to growth that went beyond what customers could increase. In addition to the aforementioned problems, buyers faced longer waiting times, car delivery. Although the car was the most affordable car, people decided to buy an experienced car that was more expensive in terms of prices, but gave them social status compared to the affordable Nana. The Nano model did not have good revenues on the market because it had a brand that was the cheapest car in the world, and therefore the vehicle was considered a poor man's car, every connection to the car stigmatized the buyer, because many chose not to buy the vehicle, especially those who had more money than middle-income people.

The concept of reverse innovations highlights a good standard when it comes to products, while based on cost reduction, but the final product must meet acceptable safety standards. Incidents of car fires have become uncontrollable and have raised serious concerns among potential buyers and buyers who already owned the vehicle. Aggrawal (2014) recalls that Nano had no basis to protect the product itself and the users of the product. Product cost-saving features, such as omiting the tank cap, have made the vehicle prone to fires and risked endangering the lives of customers, owners and passengers. Kumar (2018) shows that quite a few Nano models have caught fire, leading general consumers to question the safety of people, especially consumers. The fact that the marketing strategy for Nano work out as planned and this led to the massive reduced sales of the car compared to what had been projected.

\section{Conclusion}

The results of this study clearly show that Tata Nano's revolutionary innovation was first used in the emerging economies of India's local customers before it was launched in "rich countries". The Tata Nano was a low-cost car created as a result of the opposite innovation and wanted to provide a safe means of transport compared to a motorcycle with a limited population. In addition, the success of the concept was reflected in the reduction of product costs, the hiring of a team of experts and energetic engineers, the creation of synergies in supply chains and cooperation with financial institutions. played a key role in the success of the revolutionary innovation. However, the company faced many challenges, from safety problems caused by fires that caught the car, exacerbated by delays caused by longer waiting times and stigma associated with the car as a car with a car. Poor man. In any case, if reverse innovation is properly implemented, more can be achieved in emerging economies.

\section{Reference:}

Aggrawal, Y (2014) Reasons why Nano did not take off as expected. http;//www.letuspublish.com (accessed 10 January 2020)

Corsi, S 2012, Reversing the International Flow of Innovation: How Does Chinese Market

Trigger Reverse Innovation? Doctor of Philosophy, Scuola Superiore Sant'Anna, http://www.phdmanagement.sssup.it/documenti/awarded/corsi thesis.pdf (accessed 12 December 2019)

Corsi, S, Di Minin, A \& Piccaluga, A 2014, 'Reverse Innovation at Speres: A Case Study in China', Research Technology Management, vol. 57, issue 4, August, pp. 28-34, (online EBSCOhost

Christen, C.M (1997). The innovators dilemma; when new technologies cause great firms to fail. Harvard Business Review

David, R (2010). Tata Nano unveils its \$2,500 car. http;//www.forbes.com (accessed 14 February 2020)

Govindarajan, V (2009). What is reverse innovation? Vijay Govindarajan's blog http;//www.tuckdartmouth.edu (accessed 14 February 2020)

Govindarajan, V (2012) . A Reverse innovation playbook. Harvard Business Review- April pp120-124

Govindarajan, V (2010). The case of 'reverse innovation' now. Business week online pp 13

Immelt, J.R, Govindarajan, V and Trimble, C (2009). How GE is disrupting itself. Harvard Business Review, 87(10); 56-65

Kumar, Arjun (2017). Tata Nano sales at an all-time low, 174 units sold in March. http;//www.motorbeam.com (accessed 10 January 2020)

Soni, P 2013, 'Reverse Innovation: Create Far from Home, Win Everywhere', South Asian Journal of Management, vol. 20, issue 4, December, pp. 160-163, (online EBSCOhost) 
Utterback, J M (2004). The dynamics of innovation. Educause Review, January-February, pp 42-51

Von Zedtwitz, M (2004). Managing foreign R and D laboratories in China; R and D Management, 34(4); 439-452

Williamson, P (2010). Cost Innovation; preparing for a ‘value-for money' revolution. Long range planning.43 (23); 343-353

Von Zedtwitz, M, Corsi, S, Søberg, PV \& Frega, R 2014, 'A Typology of Reverse Innovation 'Journal of Product Innovation Management, vol. 32, issue 1, June, (online Wiley Online Library)

Zeschky, M, Widenmayer, B \& Gassmann, O 2014, 'Organising for reverse innovation in Western MNCs: the role of frugal product innovation capabilities', International Journal of Technology Management, vol. 64, issue 2-4, March, pp. 255-275, (online EBSCOhost

Zeschky, MB, Winterhalter, S \& Gassmann, O 2014, 'From Cost to Frugal and Reverse Innovation', Research Technology Management, vol. 57, issue 4, August, pp. 20-27, (online EBSCOhost) 